\title{
ASSESSMENT OF SKINFOLD THICKNESS EQUATIONS IN ESTIMATING BODY COMPOSITION IN CHILDREN WITH INFLAMMATORY BOWEL DISEASE
}

\author{
C. Callias ${ }^{1}$, T. Chatton ${ }^{1}$, P.M. Marques - Vidal ${ }^{2}$, J. Ezri ${ }^{1}$, A. Nydegger ${ }^{1}$ \\ ${ }^{1}$ Pediatric Gastroenterology, Hepatology and Nutrition ${ }^{2}$ Institute of social and Preventive Medicine (IUMSP) \\ University Hospital Lausanne, Lausanne, Switzerla
}

\section{BACKGROUND:}

Growth is a central process in paediatrics. Weight and height evaluation are therefore routine exams for every child but in some situation, particularly inflammatory bowel disease (IBD), a wider evaluation of nutritional status needs to be performed.

Twenty-five percent of Crohn's diseases (CD) are diagnosed during puberty, with growth failure often being the predominant initial manifestation.

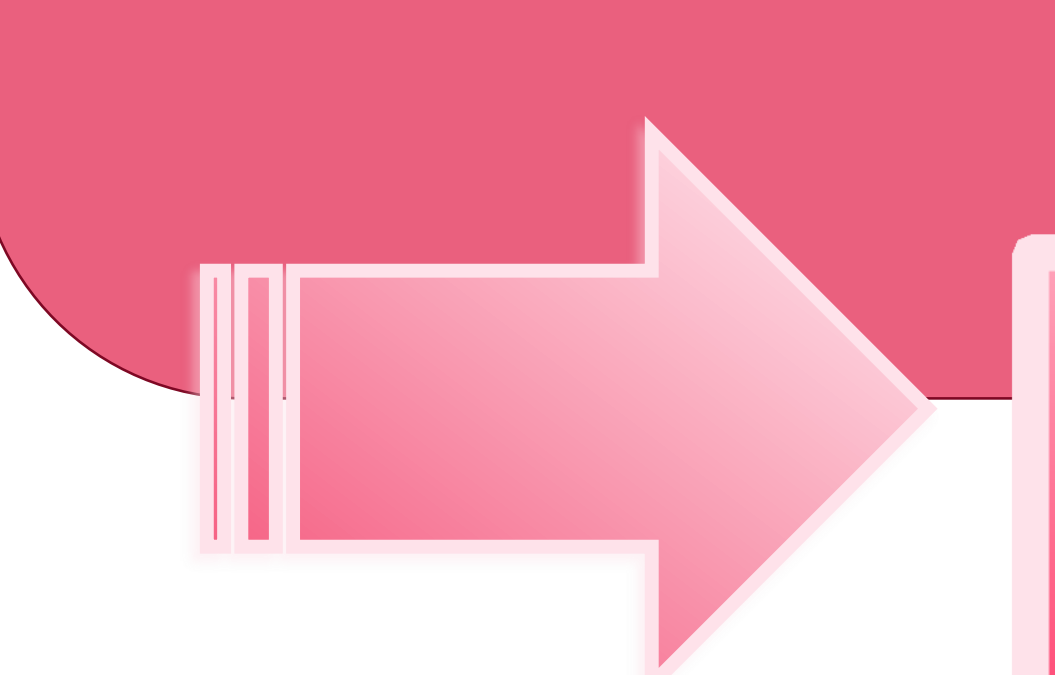

OBJECTIVES: To assess the accuracy of skinfold equations in estimating body fat percent in children with inflammatory bowel disease, compared with a gold standard method: Dual energy $x$-ray absorptiometry (DEXA).
The underlying mechanisms of growth retardation are not fully understood but may be primarily related to malnutrition and to the strong inflammatory reaction occurring during active disease.

Assessment of body composition therefore is crucial in order to maintain acceptable growth using the following techniques: Dual-energy-x-ray absorptiometry (DEXA), bio-impedance-analysis (BIA) and anthropometric measurements (skinfold thickness), the latter being the easiest available and most cost-effective one.

\section{PATIENTS AND METHOD: (figure 1)}

21 patients with inflammatory bowel disease were assessed ( 11 females, 10 males 15 with Crohn's disease and 6 with ulcerative colitis). Mean age was 14.8 years (range 12-16 years).

Body composition of these children was assessed using the following anthropometric measurements: weight, height, BMI and skinfolds thicknesses (biceps, triceps, subscapular and suprailiac).

The following 5 published equations were used in order to calculate Body Density (D) Deurenberg (1), Weststrate (2), Durnin \& Rahaman (3), Johnston (4) and Brook (5). FM percentage then was calculated using the equation from Deurenberg (1).

$D=$ coefficient 1 - coefficient $2 \times \log ($ sum of 4 skinfolds $)$ - coefficient 3 Coefficient 1, 2 and 3: vary according to author, sex and Tanner scale.

$$
\text { FM } \%=\frac{562-4.2 \times(\text { age }-2)}{D}-(525-4.7 \times(\text { age }-2))
$$

Deurenberg equation's to assess \%FM from density.

$$
(\text { FFM } \%=100-\text { FM \%) }
$$

Fat mass also can be assessed directly from skinfolds using the equation from Slaughter(6).

FM $\%=$ coefficient $1 \times($ tric + subsc $)-$ coefficient $2 \times(\text { tric }+ \text { subsc })^{2}-$ coefficient 3 Coefficient 1, 2 and 3: vary according to sex, Tanner scale and skinfold sum.

The results of these 6 equations then were compared with DEXA, serving as gold standard. The statistical analysis was performed using Lin's concordance correlation, The Bland Altman limits of agreement method, the Spearman correlation and the Bradley-Blackwood test. Calculations of mean, SD, z-score, Absolut errors, min and max values were also performed.

Figure 1:

SKINFOLD THICKNESS Technique:

$\rightarrow$ Two compartment model: (FM FFM)
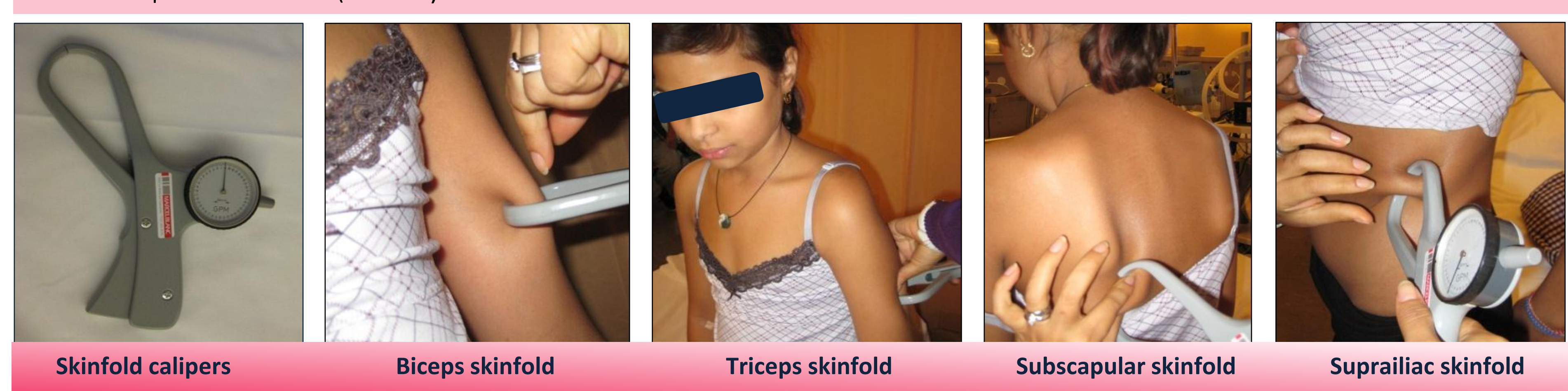

\section{Skinfold calipers}

$$
\text { Biceps skinfold }
$$

\begin{tabular}{|l} 
DEXA \\
+ validate gold standard \\
for healthy children \\
$+\quad$ good reproducibility \\
and accuracy \\
$-\quad$ expensive \\
$-\quad$ limited accessibility \\
$-\quad \begin{array}{l}\text { small irradiation of } \\
\text { subjects tested }\end{array}$ \\
\hline
\end{tabular}
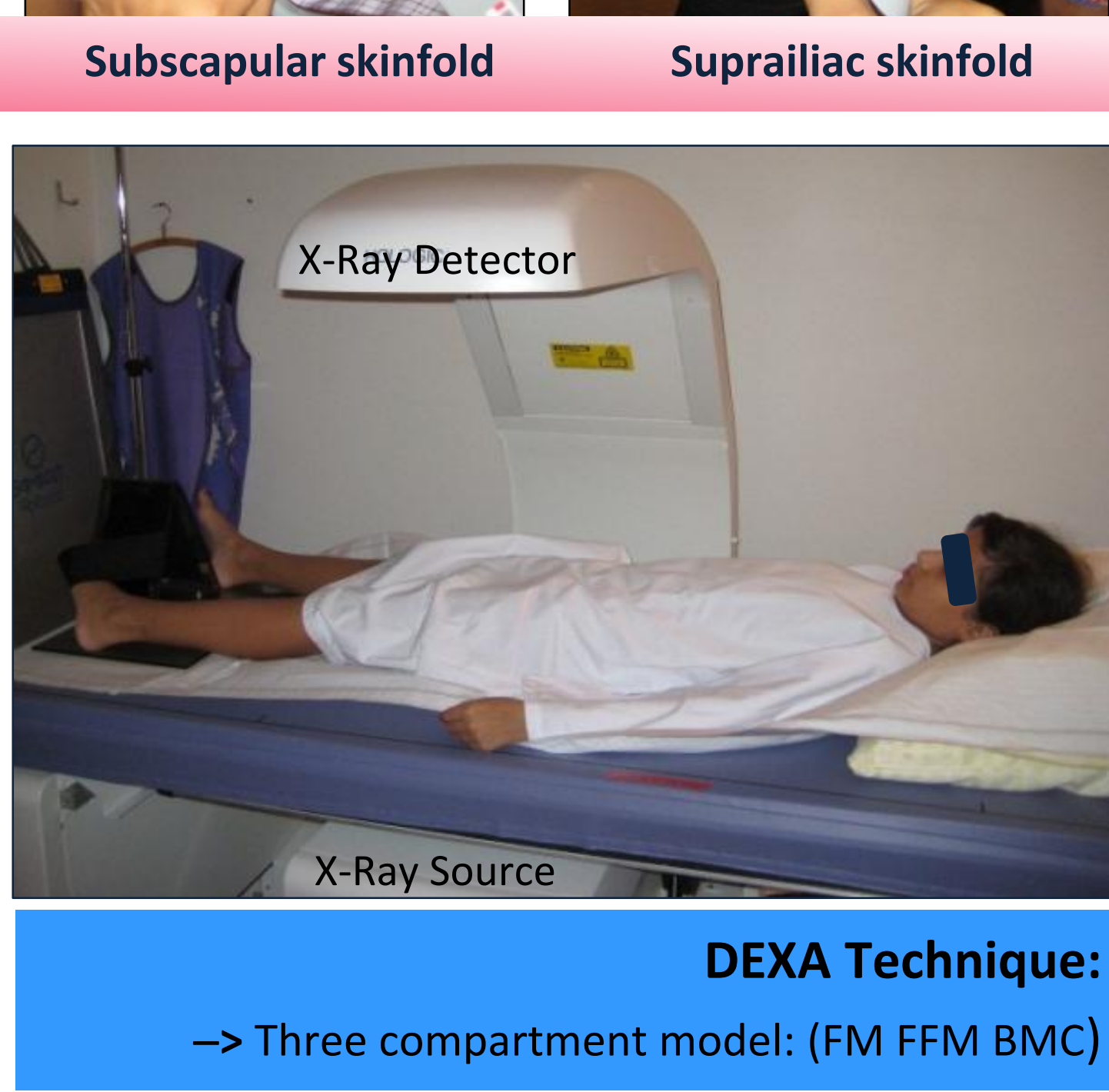

inexpensive

non invasive

portable

lack of accuracy with healthy children

reported by some authors

non valid in obese childre

need a trained observer

any different equations, depending on

author, age, sex, Tanner scale

\section{BIBLIOGRAPHY:}

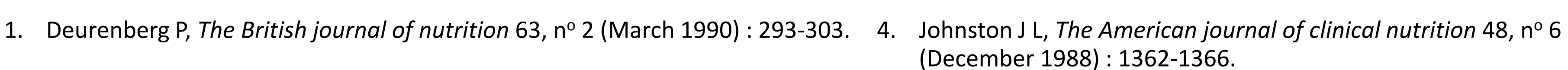

\section{RESULTS}

Results of agreement between body composition assessed by skinfold equations and DEXA are summarized in table 1.

Overall, the results of the Durnin \& Rahaman equation correlated best (Spearman and Lin test: table 1 and figure 2) with DEXA

In the Bland-Altman analysis (table 1 and figure 3), the Durnin \& Rahaman equation showed the second smallest difference from the reference values and also the second smallest correlation between difference and mean.

Finally, the Durnin \& Rahaman equation was the only equation to present a non-significant Bradley-Blackwood test.

Because of the limited sample size ( 21 children) both sexes were analysed together. In the future, evaluation of theses equations separately for IBD Females and Males should be performed as well as factor influencing individual variability.

\begin{tabular}{|c|c|c|c|c|c|c|c|c|}
\hline & \multirow{2}{*}{$\begin{array}{l}\text { SPEARMAN } \\
\text { Correlation }\end{array}$} & \multicolumn{2}{|c|}{ LIN'S CONCORDANCE } & \multicolumn{3}{|c|}{ BLAND-ALTMAN Limits of agreement } & \multicolumn{2}{|c|}{$\begin{array}{l}\text { BRADLEY- } \\
\text { BLACKWOOD }\end{array}$} \\
\hline & & Coefficient & $95 \% \mathrm{Cl}$ & Difference & SD & Correlation $\S$ & Test & P-value \\
\hline Deurenberg & $0.852 * * *$ & 0.702 & $0.512-0.891$ & -3.6 & 4.2 & -0.343 & 9.84 & $<0.001$ \\
\hline Weststrate & $0.898 * * *$ & 0.850 & $0.734-0.966$ & 2.5 & 3.3 & 0.003 & 5.62 & $<0.05$ \\
\hline Slaughter & $0.906 * * *$ & 0.848 & $0.744-0.952$ & 0.003 & 4.9 & 0.570 & 4.57 & $<0.05$ \\
\hline Durnin \& Rahaman & $0.915 * * *$ & 0.871 & $0.764-0.979$ & -1.0 & 3.6 & -0.033 & 0.80 & 0.46 \\
\hline Johnston & $0.919 * * *$ & 0.810 & $0.676-0.945$ & -3.4 & 3.3 & -0.040 & 10.5 & $<0.001$ \\
\hline Brook & $0.900 * * *$ & 0.876 & $0.779-0.972$ & 1.8 & 3.6 & 0.355 & 4.18 & $<0.05$ \\
\hline
\end{tabular}

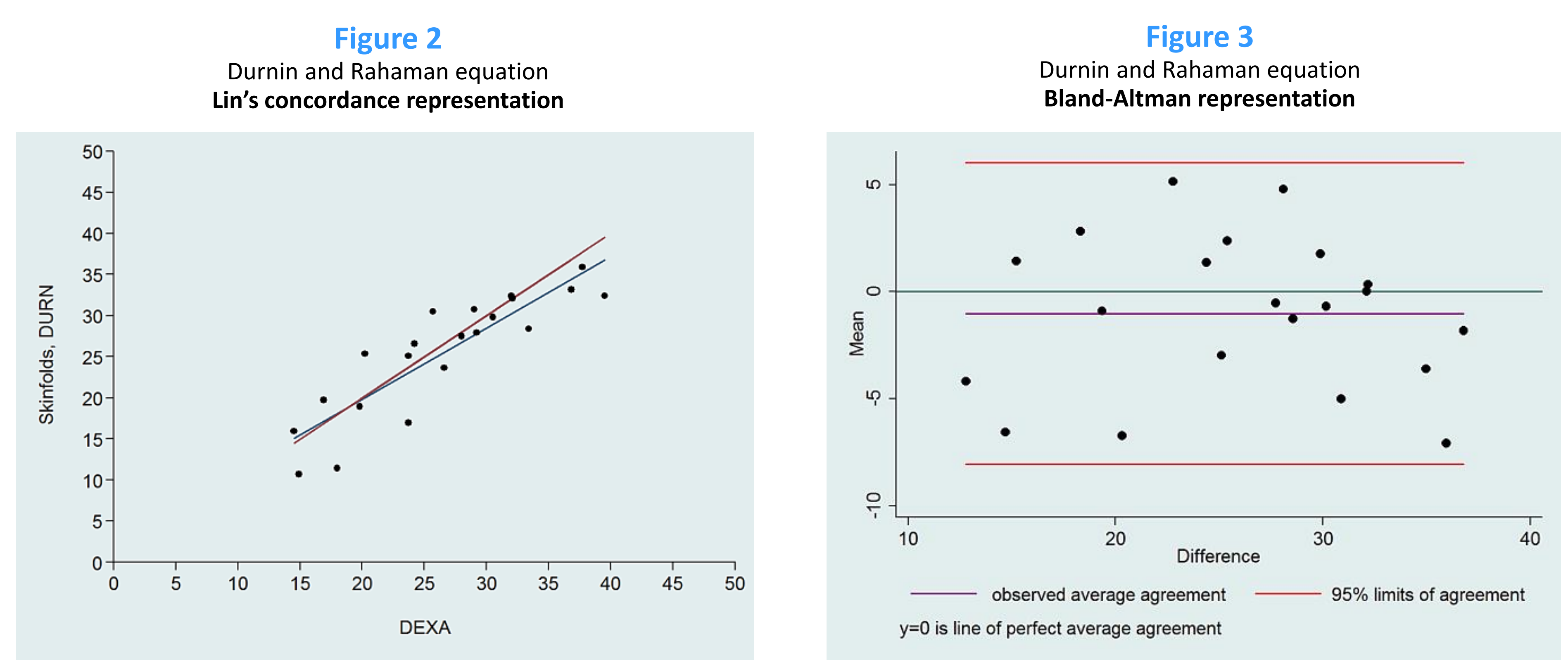

Table 1: results of the agreement between body composition as assessed by skinfold equations and DEXA

\section{CONCLUSION}

Evaluation of body composition in children with IBD was most accurate compared to DEXA using the Durnin and Rahaman skinfold equations. 